\title{
Constraining Constructions: Low-Income Fathers' Perceptions of Fathering their Adolescent Daughters
}

\author{
Elmien Lesch ${ }^{*}$ and Adiela Ismail
}

\author{
Department of Psychology, Stellenbosch University, PBX1, Matieland, 7602, South Africa
}

\begin{abstract}
Fathers have the potential to play an important role in the development of their daughters. Paternal involvement has been shown to significantly affect the emotional well-being of daughters during their adolescent and young adult years. However, internationally and nationally, research is limited in terms of the number of studies on the relationship between fathers and adolescent daughters. It is also mostly based on daughter's reports and often does not include father's perspectives. We interviewed low-income fathers who lived in a Cape Winelands community in South Africa about being fathers to daughters. A social constructionist approach to fatherhood informed this explorative and community-specific study. We used a qualitative design with semi-structured interviews and thematic analysis. Similar to other fatherhood studies, our participants' constructions of fatherhood revolved around the roles of disciplinarian, provider, protector and head of the household. Traditional roles emerged not only for the fathers but also in their constructions of their wives and daughters. Father-daughter relationships are important gender construction sites that influence daughters' future interactions and relationships with men and it is crucial that the reproduction of such traditional gender roles in homes should be addressed to empower women. Our findings also suggest that fathers tend to minimize physical demonstrations of affection towards their daughters and may need guidelines for appropriate interactions in this regard.
\end{abstract}

Keywords: Fathers' perspectives, father-daughter relationships, gender constructions low-income, social constructionist, South Africa.

\section{INTRODUCTION}

Although some fatherhood researchers question the evidence of the positive impact of father presence on children and point out the possible negative effect of father's presence on children's development [1], there is a considerable agreement that fathers can positively influence the development of their daughters. Paternal involvement has been found to significantly affect the emotional well-being of daughters during their adolescent and young adult years $[2,3]$. Daughters of responsible fathers tend to be more selfconfident, self-reliant, and more successful in peer relationships, schools and their careers, than daughters of irresponsible fathers [4-6]. Research also shows an association between lack of paternal involvement and problem behaviors such as substance abuse and delinquency [7, 8]. Katz et al. [2], however, stress that it is not the involvement of the father per se, but daughters' perceptions of paternal involvement that best predict the effect of paternal involvement. Furthermore, paternal involvement seems to have positive effects only on daughters in healthy, adaptive, and close father-adolescent daughter relationships $[9,10]$.

The quality of fathering has been shown to play a role in the quality of daughters' romantic relationships [11]. In fact, several studies have shown that fathers have a greater impact than mothers on daughters' abilities to trust, enjoy and relate

*Address correspondence to this author at the Department of Psychology, Stellenbosch University, PBX1, Matieland, 7602, South Africa;

Tel: +27 21 8083466; Fax: +27 21 8083584; E-mail: el5@sun.ac.za well to males in their lives [12, 13]. It is within fatherdaughter relationships that daughters learn how to interact with members of the opposite sex. This entails the setting of boundaries, romantic and social attachment, as well as trust and communication [3, 4]. Fathers' interactions with spouses or significant others provide a mirror for their daughters of both the positive and negative aspects of romantic relationships. This could be an important influencing factor in daughters' future interactions in romantic relationships with men $[3,11]$. Daughters' perceptions of fathers as open and non-judgmental promote their interaction with their fathers and provide a setting for positive interactions with males. Daughters who experience their fathers as supportive and understanding increase their ability to decline unwanted sexual advances [2].

Fathers and daughters, however, often experience difficulties in establishing mutually satisfying relationships. Research indicates that father-daughter relationships are not as close and self-disclosing as mother-daughter relationships [15-17]. The South African daughters in Koen's [18] study experienced their relationships with their fathers as more negative than their relationships with their mothers. They reported their relationships with their fathers as argumentative and lacking in communication. Although the South African fathers in Dunkley's [19] study wanted better relationships with their daughters, they found it difficult to understand their daughters' behaviors and to be emotional role models for them.

The relationship between fathers and daughters changes as girls enter into late adolescence. As girls move into this 
stage, fathers tend to distance themselves from their daughters and are less available to them as they are less able to relate to their daughters' experiences and development $[17,20]$. The quality of father-daughter relationships also tends to deteriorate over time while mother-daughter relationships strengthen [21]. Adolescent daughters often describe their fathers are overprotective [17]. Way et al. [17] propose that as fathers are not able to talk to their daughters about intimate topics and do not show them affection as they grow older, they try to compensate by showing affection and love for their daughters through protective measures. This overprotective behavior, however, is both a source of connection and conflict in father-daughter relationships [1]. Although many daughters report that they have loving father-daughter relationships or that they know that their fathers loved them, they desire a more meaningful, personal, and closer relationship with their fathers [17, 22]. Research also indicates that fathers recognize the importance of paternal involvement but do not always know how to be involved in relationships with their daughters [23].

Internationally and nationally, research on fatheradolescent daughter relationships is not only limited in terms of the number of studies, but also limited in that it is mostly based on daughters' reports and often does not include fathers' perspectives $[15,17,22]$. This may be due to the general difficulties in obtaining father participation in research and the additional costs it adds to child development research [24]. Although a number of recent South African fatherhood studies have included fathers as participants, these studies have not specifically examined father-daughter relationships [25-27]. Given the importance of father-daughter relationships for the well-being of daughters, and the importance of accessing fathers' own views, we interviewed fathers who lived in one specific Cape Winelands community about being fathers to daughters.

A social constructionist approach to fatherhood informed this explorative, community-specific study. This approach views father-daughter relationships as social psychological phenomena that involve interactions between fathers and daughters. The ways in which these interactions are experienced depend on a multiplicity of factors [28]. Social constructionism emphasizes that fatherhood notions and practices are informed and shaped by history, culture and other social contexts in which people live and from which they draw their personal constructions [29, 30]. Fatherhood constructions are also intertwined with prevailing masculinity constructs [29]. Given the multiplicity of factors involved in fatherhood constructions, experiences as well as meanings of fatherhood are unique and dependent on the individual's context [31]. Social constructionists are interested in exploring these unique experiences and often use qualitative methods to collect rich data on people's meanings and experiences [32]. Our study aimed therefore to foreground the understanding and experience of fatherhood of the fathers living in one specific community.

The community in which we conducted this study is a Cape Winelands community. Most of the inhabitants of this community are 'Colored' ${ }^{1}$ and employed in unskilled work positions [33]. Local research indicates that mainstream Western gender roles and relations prevail in these economically disadvantaged, historically disenfranchised Western Cape communities [34]. These gender roles are characterized by male dominance and female subservience and gendered division of labour in the home $[33,35,36]$. It is therefore likely that the fatherhood constructions of men living in these communities will be informed by such dominant gender constructions. Furthermore, fatherhood is often the most readily available source for affirming masculinity in such impoverished communities, due to the restricted access to other resources such as money [37, 38]. Men who are in such marginalized positions within society may see fatherhood as a means of attaining an adult masculine identity, without necessarily being able to ' $b e$ ' a father for their children [39-41]. According to Smit [35], however, there is a movement in these communities towards men being more involved in both family and domestic contributions and they are therefore in some ways demonstrating alternative constructions of fatherhood.

\section{METHODS}

The Stellenbosch University Research Ethics Committee granted ethical clearance for this study. The study utilized a qualitative design with semi-structured interviews and thematic analysis. This allowed for an in-depth examination of fathers' perceptions and experiences of being a father to a daughter [32].

\section{Participants}

Five Colored, Afrikaans-speaking fathers of adolescent daughters living in one low-income Cape Wine lands community participated in this study. Similar to the challenges in locating and obtaining fathers' participation highlighted by West [24], we also had difficulties in locating and obtaining participation from fathers. A local community worker helped us to recruit five initial participants. Two of these fathers, however, did not arrive for the scheduled interviews, nor could they be reached to reschedule interviews. Andries, the first father we interviewed, offered to recruit further participants. Below is a brief description of each father:

Andries is a 47 year old married man and a father of five children; four daughters and a young son. He completed grade seven and worked as a bus driver. He presented himself as a dedicated father, and often spoke about the sacrifices he made for his family. He spoke about being protective of his daughters and also showed concern for the two female interviewers' safety. He offered to recruit more participants and liaise with them regarding appointment times as he felt that it was not safe for two females to be alone in the community.

\footnotetext{
${ }^{1}$ The term "Colored" was used in the Apartheid era and is still used today to refer to persons of mixed racial descent. Although this usage is contentious and many argue for the need to move beyond it, it continues to be used to designate race or ethnicity. We want to emphasize that we do not use this term to reinforce Apartheid ideology. Our aim is to focus attention on and acknowledge the specific cultural, political, and economic history and context of this specific ethnic group in South Africa.
} 
James is a married 55 year old father of two daughters. He left school after the completion of grade nine due to his family's strained financial situation. He is a taxi driver who works long hours to provide for his family. His eldest daughter is 17 and lives away from home to be closer to her work. She had to leave school at the age of 15 to earn an extra income for the family. He appeared to be a gentle man and depicted himself as a father never angered, frustrated or even disappointed by his children.

Kallie is a 45 year old man and a father of 13 children. He completed grade eleven. He lives in a small home with his fiancé, son and grandchild. He spent a number of years in jail and at the time of the interview he was on parole working as a gardener. Unlike the other fathers, Kallie does not reside with his 16-year old daughter and telephone calls are their only mode of interaction. It appeared important to him to be viewed as a good father and to receive such affirmation from the interviewers. He seemed sad and disappointed when he talked about his limitations as a father to his daughter.

Petrus is 54 years old, married and the father of two children, a son and a daughter. He completed grade ten. His finances are strained, as he is a retrenched farm worker who receives a monthly disability grant. Both Petrus and his wife are unemployed, and his 18-year old daughter refuses to attend school. The family spends its days watching television - mainly sports and soap operas. His open account of when his daughter reported him to the police for physical punishment and the impact this had on their relationship surprised both interviewers.

Mannyis a 62 year old recent widower and has five children. He completed grade eleven. He resides in a small one-bedroom home where he sleeps on the kitchen floor on a mattress, so that his daughter and granddaughter can sleep in the bedroom. The house does not have running water or electricity. Manny and his daughter use candles for light and have to fetch water daily from a tap a distance away. As a retired farm worker, Manny receives a government pension and with the help of his youngest son, supports himself, his 18-year old daughter and granddaughter.

\section{Data Collection}

Having obtained a written informed consent from the participants, we conducted the first and follow-up interviews with them after hours at one of the local church buildings. When asked about their motivation for participating in the study, participants said that they were interested to talk about their own fatherhood as they have never had the opportunity to do so. We conducted the interviews in Afrikaans, audiorecorded them, and used open-ended questions to elicit responses, e.g., tell me about your daughter; what is it like for you to be a father to her? What is difficult about being a father to her? What is your understanding of what it entails to be a good father?

At the time of the research, we could not locate an experienced interviewer who shared the same demographic factors as the participants. We therefore used the interviewers that were available to us and committed to the study: an Afrikaans-speaking Master's student in Psychology and the second author, an English-speaking, Colored Masters student in Clinical Psychology. We are aware that the incongruence between the young, middle class, female, postgraduate university students and the Colored, lowincome fathers with relatively low educational levels has influenced the data, data analysis and findings in various ways. We, however, had the opportunity to compare the quality of these interviews to interviews conducted by Colored, male interviewers with a further 13 fathers and found the content and themes similar to those in the current study.

\section{Data Analysis}

We used the method of inductive thematic analysis by Braun et al. [42] to analyze the interview material after transcribing and checking interviews for accuracy. This method entailed generating themes from the fathers' transcribed interviews that were close to the data itself. The researchers did the analysis using the steps provided by Braun et al. [42] as a guide and paid careful attention to capture all meanings when coding each interview. We collated the codes of each interview into preliminary themes to ease the process of finding main themes in the entire data set. Main and sub themes were then identified from the codes and the preliminary themes by reorganizing the codes and preliminary themes into what seemed like collective ideas apparent in most of the interviews [42]. Finally, we named all themes bearing in mind that the name of the theme had to capture the essence of the data extracts it used [42]. Via this process, five themes were generated in total: Father as a disciplinarian; Father as a protector; Father as the head of the household; Constructions of daughters; and Expressions of affection.

The quality and accuracy of the data analysis was checked and improved, firstly by comparing the two interviewers' codes and themes with each other, and secondly, by comparing the supervisor's codes with the two interviewers' codes; and resolving the differences.

\section{RESULTS AND DISCUSSION}

\section{The Father as Disciplinarian}

Fathers as disciplinarians featured pertinently in the participants' fatherhood constructions. The fathers who grew up with their own fathers described them as 'good fathers' because they remembered them as strict men who disciplined with fairness, and taught their children consequences and lessons about life:

Kallie: "My father was very strict and he loved us very much. We could never curse in front of him. When we did something wrong he did not spank us first, he always talked with us first or after the hiding he talked with us and explained to us why he gave us a hiding. He did not make fish of the one and meat of the other. He always loved us the same".

Petrus: "I will be a good example just like he was for me... You see, I always tell them what my father told me, my child, check and recheck... It is my job as father to do this, to discipline her. It is not punishment in my view, only rules. I always tell her that this is the way 
I was brought up and I will raise her the same way".

James: "My father taught me that I must be a man and a father for my children".

Two of the five participants did not grow up with their biological fathers. These men wished to be the kind of father they desired for themselves. Andries, for example, grew up with his grandparents and said that he desired a strong father who provided discipline and structure:

\section{"My grandfather and grandmother brought me up like a spoilt child... I always longed for that father-figure, but I never had one. I had that, but not one of my own, if you know what I mean. It is what makes me such a strong father figure...because I want to give them what I wanted from my father".}

The principle of intergenerational transmission of parenting proposes that the way that fathers perform the role of fathering is related to their experiences of their own fathers [43, 44]. Within the present study, fathers who perceived their own fathers as uninvolved or absent placed a greater emphasis on not repeating this style of fathering. This is in accordance withTamis-LeMonda and McFadden [45] who posited that fathers who had previous experiences of uninvolved fathering, had a greater motivation to actively partake in their children's lives. The participants who had a positive recollection of their own fathers as fair disciplinarians, seemed to emulate this role in their own fathering.

\section{The Father as Protector}

All the fathers spoke at length about protecting their daughters. Within this low-income community there was great emphasis on the dangers of the outside world. Examples of dangerous incidents in the community were highlighted to daughters and general warnings of danger were often issued:

Andries: "Yes, you know about life outside. They are often told to see what happened outside. When they want to go out, I first give them a lecture".

More specific warnings of dangers were aimed at protecting daughters against predatory men. Messages such as 'sex is dangerous' and 'beware of men' are given to daughters. Fathers tried to protect their daughters from men and sex by enforcing rules regarding curfews and wanting to know the daughters' whereabouts. It was apparent that fathers felt their daughters were vulnerable and could be taken advantage of:

Kallie: "I told her to open her eyes and not to fall for any man. You see, the young men see when you are easy and then they use you".

James: "If he is a good guy then I first want to meet his parents to see from what kind of home he comes - not just somebody off the street or someone that you met one evening. That is not right and that is no future for her. It must be a man that can look after her".
They also believed that their daughters needed men to guide and protect them:

Manny: "I need to go with her, to tell her what to do, or what not to do. She needs to be protected, she needs a man that can protect her and this is now my responsibility until she finds a man to do this".

Fathers from this community were very aware of the specific community they resided in. This community was described by these fathers as afflicted by poverty, unemployment, substance abuse and the various social problems associated with this:

Kallie: "I see the fathers here in this place all they do is drink on the weekend and leave their children to look after themselves. What is worse than that is they take them to the yard (shebeen) and they drink there and the children are around all those people. Don't they think about their children?"

Andries: "There are girls here in the community, but I looked and there is no father, it's like their fathers have left them, they don't care what happens to their daughters. They are just gone".

James: "Yes, they easily talk to us (parents). When they are with us in the evening and when there is peace then the conversation broadens en (and) we talk about the issues out there and things that are wrong out there".

As Tamis-LeMondaet al. [45] also found, fathers living in a low-income community tend to place importance on their role as the protector of their children because they are so aware of the dangers of the communities they reside in.

\section{The Father as Provider}

Financial provision plays an important role in fathers' experience of their relationships with their daughters and was often mentioned spontaneously by the men:

Kallie: "Sometimes then she phones me and says daddy this happened and that happened, my mother said this, then I say my child it is all right put your mother on the phone, then I talk to her mother and ask her what have you done to her now? Then she says but she (daughter) want this and this, then I say to her give it to her then I will pay the money into your account, buy it for her, don't tell her that there is no money".

Petrus: "When she asks me, I need to provide. This is what I think a father needs to do. I do not know what other fathers do or do not do, but this is what I believe a father should be".

Manny: "...how can I put it, to make sure there is a roof and something on the table, food on the table, to make sure there is something to put on, a dress or pants. If I have money, I will do this for her". 
James: "My father was a hardworking man like I am. I do not stay away from work without a reason and I give my family all the money that I earn. When I was a child we had to be satisfied with what my father gave us and my children is also like that. If I do not have money then they understand".

None of the fathers spoke out of their own accord of providing emotional support to their young daughters. It was clear that they perceived financial provision as the primary medium through which they showed love and care to daughters. When they were asked to reflect on how their daughters may perceive them and their roles in their daughters' lives, they said that their daughters would place emphasis on their role as a financial provider. They did not speak of other needs, e.g. emotional support. This could be interpreted in a number of ways: e.g., it could mean that emotional support did not feature in their understanding of fatherhood; they did not have the language to participate in a discourse of fathers as emotional carers; or they did not consider emotional support to be one of the most important components of fatherhood. All of these possibilities could, however, be partially explained by the prevalence of traditional gender roles in this community which prescribe that mothers are the primary emotional carers and fathers are the primary financial caregivers $[36,37,46]$. It is also likely that the financial or provider role of fathers in low-income communities is sustained and emphasized more than in affluent communities [37, 46].

As the fathers in our study equated being a good father to their ability to provide financially, it distressed them if money was not readily available. According to Coley [4], when fathers in low-income families with traditional parental roles perceived themselves as inadequate providers, they reduced interactions with their children and family. Within this community the economic pressures that these men face and the need to be providers to their children meant that many of the fathers spent little time with their children. This became a double edged sword: Fathers who were unable to provide for their children were distressed, and those who could provide financially by working longer hours, also felt distress due to the limited time spent with their children.

Petrus: "There has been an instance like that, when I did not have money to give and I felt terrible, really terrible... Yes, I feel terrible and it was difficult for me to tell her that I didn't have money".

Andries: "You know when I worked and went away for the long distance trips I felt like I was missing out on my children's lives. I called them every day, I knew what was happening but when I was not there I felt that there was a gap between them and me".

However, as Roy [37] posits, the fathers in this study who could not contribute financially made other contributions, such as doing heavy housework that required physical strength, e.g., fetching water or doing heavy laundry. They themselves, however, did not seem to value these contributions as important. Mavunga [46] points out that the fathers who participated in his study also viewed financial provision as the full extent or most important demonstration of fatherhood and that other demonstrations were not deemed equally valuable.

\section{The Father as Head of the Household}

The traditional role of the father as a head of the household emerged in the interviews. Although many of the participants described the decision-making process as a collaborative one between husband and wife, they stated explicitly that fathers made the final decision.

Andries: "You need to work with your wife to make the best of the situation. You should not allow her to make decisions on her own, to say this is how it is going to be and that is that. This is where the father figure should be involved to say it was not the right decision, it will not be like that".

It also seemed as if the participants usually approached outside parties or spoke to authority figures in their children's lives in case of problems:

Petrus: "I do not know at this point what the problem is, whether it is problems with the teachers or with the children. I asked the teachers and they said that she is lonely".

Andries: "You know I went to the principle to try and sort this problem out about her getting beaten up. I told him to sort it out and take control of his students, this is not right".

The participants also regarded themselves as problem solvers in their families:

James: "A mother and daughter have a different kind of a relationship. Sometimes the mother is more cross with them ... and then the father must go to the mother and I must go and find out what is going on and why are they cross with each other and talk it over and come to an agreement. She (mother) puts pressure on me and says I must talk to the children..."

Most participants related that their children and specifically their daughters went to their mothers first when they experienced a problem. It appeared as if mothers provided emotional support as well as mediated the conversation and connection between fathers and daughters. None of these fathers appeared to have a problem with this; many stated that their wives were better equipped to handle the emotional aspect of the problem:

Andries: "I will say it depends on the type of problem, what the problem is about, but in 90\%, 95\% many instances she will first tell her mommy. Her mommy will listen to the problem and will only then include me".

Petrus: "You see, it goes like this, she will go to her mother and talk to her mother and then her mother will come to me".

James: She will first go to her mother, then her mother will come to me and we will discuss it and decide what to do". 
Although all the participants believed that they had 'open' relationships with their daughters and their daughters were able to speak to them about everything, the quotes above indicate otherwise. It seems that mothers were the first port of call in distress and that they facilitated a more digestible version of the daughter's problem or situation for the ears of the father. This is similar to other research [47] which also indicates that daughters would more likely turn to their mothers in times of emotional need.

\section{The Constructions of Daughters}

The fathers felt that raising a daughter differed from raising a son. They believed that daughters needed more discipline, attention and structure:

Petrus: "You see, a father needs to be strong when he has a daughter. A daughter is a little bit difficult. For example, I will tell a daughter that she can go there but she cannot go there in the evening, she has to go there in the afternoon, yes, that is why I say it is different. My son is fine, but with her there needs to be rules. They, girls, are also expensive".

Household duties assigned to daughters appeared to be gender specific and mainly consisted of domestic chores. Furthermore, daughters were described not by personality traits or personal interests, but by characteristics such as obedience and respectfulness, as well as their roles in the household.

James: "She is a responsible girl; she understands and will do as you ask... She will never do anything or go anywhere without asking".

Manny: "Then she will get up to prepare a bottle for the child and to change the child's nappies. I will take a book and read while she is busy with her things, jobs and so on. Then she prepares me breakfast and I eat and then I sit with my friends".

These quotes indicated that fathers hold traditional gender roles of men and women in terms of desired characteristics and gendered divisions of labour. These gender roles may have contributed to our impression that fathers did not seem to know their daughters on a more personal level. They struggled with interview questions pertaining to their daughters' interests, their dreams and aspirations or simply their likes and dislikes. Similarly, Nielson [48] posits that daughters, also, do not get to know their fathers well and ascribes it to the difference in communication between mothers and daughters and fathers and daughters. This was demonstrated to some extent by our participants' responses when we asked how their daughters would describe them. Many stated that their daughters' descriptions would focus on the roles they played in their daughters' lives.

Although two participants spoke about their daughters' sexual maturation process without being prompted by the interviewers, the participants did not touch on their own experience of the sexual development of their daughters. Sharpe [49] suggests that a father's perception of his daughter is colored by a sense of possessiveness and protection of her sexual innocence. Kirkman et al. [50] also found that fathers' discomfort about conversations with daughters about sexuality was a result of the tension between the protective father and the father as a man. This could explain why our participants' conversations with their daughters consisted mostly of telling them about the consequences and responsibilities of becoming a sexual being:

Andries: "Well, like I said, we are very honest and very open; we have a very open relationship. We told her to sit down and said that she is now mature and there are many responsibilities that come with it".

Conversations regarding sex centered on warnings, rules and expectations, not exploring experiences or offering a space for a dialogue between father and daughter about sex. This is in accordance with Hutchinson [51], who found that fathers' roles in communication about sex mostly involve talks about moral issues and expectations. There is, however, a dearth of literature focusing specifically on the role of fathers in sexual communication. Most of the research highlights the importance of mother-daughter communication [48]. Wilson et al. [23], however, found that adolescent girls who had a positive relationship with their fathers were comfortable to discuss issues about sexuality with their fathers, delayed their sexual activity, and had a more positive attitude towards sex during their adolescence.

\section{Expressions of Affection}

Only two participants mentioned physical demonstrations of affection without being prompted. Kallie appreciated and welcomed physical affection with his daughter:

Kallie: "Okay, I know many girls do not like that, especially when they are grown. But we have always been like that, so if I go to her and see her, then I will kiss her and give her a hug and we will walk hand in hand".

Andries seemed to appreciate the initiation by his daughter of playful physical affection/contact with him:

"Sometimes when I walk past her in the house then she will tap me on the bald spot on my head and say hallo baldy, or she will tap me lightly on the butt or trip me which is something that the other children will never do. Then I will grab her and play with her".

Petrus said affectional gestures like hugs and kisses initiated by him were restricted to special events such as birthdays:

“...I give her a hug every year on her birthday then I hug her and give her a kiss. Also the time when she was confirmed in church, yes, once a year on her birthday. So on the first of November I will give her a hug and kiss her again".

As daughters begin to mature, it seemed that some participants' comfort with physical demonstrations of affection changed. According to all the participants, their relationships with their young daughters were filled with abundance of physical affection and they often recalled moments when their 
daughters sat in their laps or walked hand in hand with them. However, as the daughters matured, participants became more reticent. Petrus said: "It is not necessary for her to get hugs and kisses every day, she is not my wife and it's not like I sleep with her."

Although participants appeared to be comfortable discussing the expression of affection in father-daughter relationships, they seemed uneasy when they were asked to expand on it or asked about how they spent time alone with daughters. This may be due to the increased attention given to father-daughter incest and sexual abuse by fathers over the past years [52, 53]. Participants may, therefore, have feared being perceived as behaving inappropriately with their daughters. Such fears and uncertainties regarding appropriate ways to interact with their daughters' developing bodies, perhaps offer an explanation to why other studies' $[17,20]$ found that fathers tend to distance themselves from their daughters when daughters enter adolescence. It therefore seems important for fathers to receive guidance regarding this relationship component.

\section{CONCLUSION AND IMPLICATIONS}

The scope of this study did not allow for broad generalizations; however, the findings generated an in-depth understanding of a selected group of fathers regarding their relationships with their adolescent daughters. Similar to other fatherhood studies [54], our participants' fatherhood constructions revolved around the roles of disciplinarian, provider, protector and head of the household. Traditional roles emerged not only for the fathers but also in their constructions of their wives and daughters. Mothers were seen as the emotional caretakers of their daughters and daughters were expected to be obedient, to take on domestic tasks and to guard themselves against predatory men and sexual activity.

Although the fathers in our study appeared to care very much about their daughters, a discourse of fathers as emotional nurturers did not feature in the interviews. Furthermore, although the fathers themselves did not articulate a limited emotional connection with their daughters and professed to feel close to their daughters, it appeared to us that fathers had limited emotional and affectionate interactions with their daughters. We did not get a sense that fathers and daughters knew each other well. It could therefore be argued that both fathers and daughters are missing out on deeper emotional connections. In the light of research findings that continuing, close and loving relationships with open communication between fathers and daughters are important in adolescent women's well-being $[2,3]$, it may therefore be important to sensitize fathers to the importance of such relationships. More importantly, fathers should be assisted to see the shortcomings in what they perceived to be 'open' and 'closed' relationships. Fathers should also be taught how to initiate a broader range of interactions with their daughters, specifically more democratic, listening and emotion-focused conversations.

Our data also indicate that as daughters matured sexually, fathers found it uncomfortable to demonstrate physical affection to their daughters. In our current society where inappropriate sexual behavior by fathers is often highlighted [52, 53], it may be useful for fathers to learn how to show appropriate physical affection to their daughters.

Our analysis shows that fathers' constructions of fathers and daughters correspond with traditional notions of masculinity and femininity $[50,55]$. This supports the argument that fatherdaughter relationships should be seen as important gender construction sites [e.g. 3, 14] that influence daughters' constructions of themselves in relation to men. It thus seems crucial for the empowerment of young women that the reproduction of traditional gender roles within this gender site should be addressed. Fathers should be sensitized in how they can contribute much more to their daughters' advancement, empowerment and sexual health than the contribution of their current protection strategies, by practicing alternative gender constructions in the parenting of their daughters. However, it should be acknowledged that men are hampered in expanding their fathering roles by powerful mainstream notions of masculinity that support males in dominant and controlling, and women in supportive and submissive roles. In these gendered notions, mothers and women are viewed as the primary emotional caretakers [50-52], and the ideal man is seen as someone who exerts power and authority, and is unemotional and invulnerable $[51,56]$. The expression of emotions by men is associated with weakness - which is considered a threat to masculinity [57]. Furthermore, financial provision has been found to be the most common form of maintaining a masculine identity [58]. Such masculinity constructions therefore support and endorse limiting roles for fathers as disciplinarians and providers. The implication is that both mainstream masculinity and fatherhood constructions should be challenged and/or replaced with alternative constructions in order to make it desirable and acceptable for men to adjust their constructions of fatherhood and to pursue father-daughter interactions that will promote daughters' agency.

\section{CONFLICT OF INTEREST}

The authors confirm that this article content has no conflict of interest.

\section{ACKNOWLEDGEMENTS}

\author{
Declared none.
}

\section{REFERENCES}

[1] Morrell R. Fathers, fatherhood and masculinity in South Africa. In: Richter L, Morrell R, Eds. Baba: Men and fatherhood in South Africa. Cape Town: HSRC Press 2006.

[2] Katz J, van der Kloet E. The first man in her life: Father emotional responsiveness during adolescence and college women's sexual refusal behaviors. Am J Fam Ther 2010; 38(4): 344-56.

[3] Scharf M, Mayseless O. Late adolescent girls' relationship with parents and romantic partner: The distinct role of mothers and fathers. J Adolesc 2008; 31: 837-55.

[4] Coley RL. Daughter-father relationships and adolescent psychosocial functioning in low-income African American families. J Marriage Fam 2003; 65(4): 867-75.

[5] Mckinney C, Renk K. Differential parenting between mothers and fathers: Implications for late adolescents. Family Issues 2008; 809: 80627.

[6] Perkins RM. Father-daughter relationships: Familial interactions that impact a daughter's style of life. Coll Stud J 2001; 35: 616-26.

[7] Bronte-Tinkew J, Moore KA, Capps RC, Zaff J. The influence of father involvement on youth risk behaviors among adolescents: A comparison of native-born and immigrant families. Soc Sci Res 2006; 35(1): 181209.

[8] Fosco GM, Stormshak EA, Dishion TJ, Winter CE. Family relationships and parental monitoring during middle school as predictors of early adolescent problem behavior. J Clin Child Adolesc Psychol 2012; 41(2): 202-13.

[9] King V, Sobolewski JM. Nonresident fathers' contributions to adolescent well-being. J Marriage Family 2006; 3(68): 537-57. 
[10] Waller MR, Swisher R. Fathers' risk factors in fragile families: Implications for "healthy" relationships and father involvement. Soc Prob 2006; 53(3): 392-420.

[11] Furman W, Simon, VA, Shaffer L, Bouchey HA. Adolescents'working models and styles for relationshipswith parents, friends and romantic partners. Child Dev 2002; 73(1): 241-55.

[12] Flouri E, Buchanan A. The role of father involvement in children's later mental health. J Adolesc 2003; 26: 63-78.

[13] Leonard L. The wounded woman: Healing the father daughter wound. Boston: Shambala 1998.

[14] Kousha M. Love and Control between fathers and daughters in Iran. Critique: Crit Mid East Stud 2002; 11(1): 91-108.

[15] Crocket LJ, Russel ST. Latino adolescents' understandings of parentadolescent relationships: Common themes and subtle differences. Gender roles in immigrant families. New York, NY: Springer 2013.

[16] Nelson T. Low income fathers. Ann Rev Sociol 2004; 30: 427-51.

[17] Way N, Gillman D. Early adolescent girls' perceptions of their relationships with their fathers: A Qualitative Investigation. J Early Adolesc 2000; 20: 309-31.

[18] Koen V. African female adolescents' experience of parent-adolescent relationships and the influence thereof on their well-being. Masters [dissertation]. North-West University: Potchefstroom, South Africa 2010.

[19] Dunkley JG. Parenting Adolescents: A Phenomenological Approach. $\mathrm{PhD}$ [dissertation]. University of the Free State, South Africa 2013.

[20] Lieberman M, Doyle A, Markiewiez D. Developmental patterns in security of attachment to mother and father in late childhood and early adolescence: Associations with peer relations. Child Dev 1999; 70(1): 202-13.

[21] Bengston VB, Roberts R. How families still matter. New York: Cambridge University Press 2002.

[22] Nielsen L. College daughter's relationships with their fathers: A 15 year study. Coll Stud J 2007; 1-11.

[23] Wilson K, Dalberth BT, Koo HP. "We're the heroes!": Fathers' perspectives on their role in protecting their preteen children from sexual risk. Perspect Sex Reprod Health 2010; 42(2):117-24.

[24] West J. The methodology of studying fathers in child development research. Appl Dev Sci 2007; 1(4):229-33.

[25] Hosegood V, Madhavan S. Understanding fatherhood and father involvement in South Africa: Insights from surveys and population cohorts. Fathering 2012; 10(3): 257-73.

[26] Richter L, Smith W. Children's views of fathers. In: Richter L, Morrell R, Eds. Baba: Men and fatherhood in South Africa. Cape Town: HSRC Press 2006

[27] Timaeus IM, Boler T. Father figures: The progress at school of orphans in South Africa. AIDS 2007; 21(7): S83-S93.

[28] Weiten W. Social behavior. In: Hague JD, Makarewycz, K, Eds. Psychology themes and variations. $8^{\text {th }}$ ed. Belmont, CA: Wadsworth 2010; pp. 663-707.

[29] Hay C, Mac enGhaill M. Men and Masculinity. Buckingham: Open University Press 2003.

[30] Nsamenang AB. In: Lamb ME, Ed. The role of the father in child development, $5^{\text {th }}$ ed. New Jersey: John Wiley \& Sons Inc. 2010.

[31] Kim B. Social constructivism. In: Orey M, ed. Emerging perspectives on learning, teaching, and technology.

[32] Creswell JW. Qualitative inquiry and research design: Choosing among five approaches. $2^{\text {nd }}$ ed. London: Sage Publications 2006.

[33] Lesch E, Engelbrecht S-K. Relationship satisfaction and gender differences in a South African farm-worker community. S Afr Rev Sociol 2011; 42(1): 58-77.

[34] Shefer T, Ratele K, Strebel A, Shabalala N, Buikema R. From Boys to Men: Social constructions of masculinity in contemporary society. Lansdowne: UCT Press 2007.

[35] Smit R. The changing role of the husband/ father in the dual-earner family in South Africa. J Comp Fam Stud 2002; 33(3): 401-15.
[36] Strebel A, Crawford M, Shefer T. Social constructions of gender roles, gender-based violence and HIV/AIDS in two communities of the Western Cape, South Africa. Sahara J 2006; 3(3): 516-28.

[37] Roy MK. You can't eat love: Constructing provider role expectations for low-income and working class fathers. Fathering 2004; 2(3): 1-21.

[38] Hendricks L, Swartz S, Bhana A. Why young men in South Africa plan to become teenage fathers: Implications for the development of masculinities within contexts of poverty. J Psychol Afr 2010; 20: 52736.

[39] Marsiglio W, Pleck JH. Fatherhood and masculinities. In: Kimmel MS, Hearn J, Connell RW, Eds. Handbook of studies on men and masculinities. Thousand Oaks /London / New Delhi: Sage 2005; pp. 249-69.

[40] Richter L, Morrell R. Baba: Men and fatherhood in South Africa. Cape Town: HSRC Press 2006.

[41] Spjeldnaes IO, Moland KM, Harris J, Sam DL. "Being man enough": Fatherhood experiences and expectations among teenage boys in South Africa. Fathering 2011; 1: 3-21.

[42] Braun V, Clarke V. Using thematic analysis in psychology. Qual Res Psychol 2006; 3: 77-101.

[43] Conger RD, Belsky J, Capaldi DM. The intergenerational transmission of parenting: Closing comments for the special section. Dev Psychol 2009; 45(5): 1276-83.

[44] Shannon JD, Tamis-LeMonda CS, Cabrera N. Fathering in infancy: Mutuality and stability between 8 and 16 months. Parent Sci Pract 2006; 6(2-3): 167-88.

[45] Tamis-LeMonda CS, McFadden KE. In: Lamb ME, ed. The role of the father in child development, $5^{\text {th }}$ ed. New Jersey: John Wiley \& Sons Inc 2010.

[46] Mavungu EM. Provider expectations and father involvement: learning from experiences of poor "absent fathers" in Gauteng, South Africa. Afr Sociol Rev 2013; 17(1): 65-78.

[47] Eggebeen DJ, Knoester C. Does fatherhood matter for men? J Marriage Fam 2001; 63(2): 381-93.

[48] Nielson L. Fathers and daughters, why a college course? Coll Stud J 2001; 35(2): 280-316.

[49] Sharpe S. Fathers and daughters. London and New York: Routledge 1994.

[50] Kirkman M, Rosenthal DA, Feldman SS. Freeing up the Subject: Tension between traditional masculinity and involved fatherhood through communication about sexuality with adolescents. Culture Health Sex 2001; 3(4): 391-411.

[51] Hutchinson MK. The influence on sexual risk communication between parents and daughters on sexual risk behaviors. Fam Relat 2002; 51(3): 238-47.

[52] Rice M, Harris G. Men who molest their sexually immature daughters: Is a special explanation required? J Abnorm Psychol 2002; 111(2): 32939.

[53] Richter LM, Dawes AL. Child abuse in South Africa: Rights and wrongs. Child Abuse Rev 2008; 17(2): 79-93.

[54] Ratele K, Shefer T, Clowes L. Talking South African fathers: a critical examination of men's constructions and experiences of fatherhood and fatherlessness. S Afr J Psychol 2012; 42(4): 553-63.

[55] ImpettEA, Schooler D, Tolman DL. To be seen and not heard: Femininity ideology and adolescent girls' sexual health. Arch Sexual Behav 2006; 35(2): 131-44.

[56] Lynch I, Brouard PW, Visser MJ. Constructions of masculinity among a group of South African men living with HIV/AIDS: reflections on resistance and change. Culture, Health Sex 2010; 12(1): 15-27.

[57] Seidler VJ. Man enough: Embodying masculinities. London: Sage Publications 2005.

[58] Tichenor V, McQuillan J, Greil AL, Contrepas R, Shreffler KM. The importance of fatherhood to U. S. married and cohabiting men. Fathering 2011; 9(3): 232-51. 